\title{
Hydrothermal Preparation and White-Light-Controlled Resistive Switching Behavior of $\mathrm{BaWO}_{4}$ Nanospheres
}

\author{
Bai Sun $\cdot$ Yonghong Liu $\cdot$ Wenxi Zhao $\cdot$ Jinggao Wu $\cdot$ Peng Chen
}

Received: 29 August 2014/Revised: 26 October 2014/Accepted: 4 November 2014/Published online: 22 November 2014

(C) The Author(s) 2014. This article is published with open access at Springerlink.com

\begin{abstract}
In this work, $\mathrm{BaWO}_{4}$ nanospheres were successfully prepared by hydrothermal process. The bipolar resistive switching behavior of $\mathrm{Ag} / \mathrm{BaWO}_{4} / \mathrm{FTO}$ device is observed. Moreover, this resistive switching behavior can be modulated by white light. The device can maintain superior stability in the dark and under white-light illumination. This study is useful for developing the light-controlled nonvolatile memory devices.
\end{abstract}

Keywords $\mathrm{BaWO}_{4}$ nanospheres $\cdot$ Resistive switching $\cdot$ Hydrothermal preparation $\cdot$ White light

\section{Introduction}

Reversible resistive-switching effect is a promising candidate for next-generation nonvolatile memories [1]. The resistive switching behavior, in which the reversible switching between a high-resistance state (HRS) and a low-resistance state (LRS) can be achieved by the applied voltage, is an attractive subject of scientific and technical research [2-6]. The resistive switching is classified into unipolar resistive switching and bipolar resistive switching [7]. The resistive switching memory cell usually has simple structure, in which an insulating oxide is sandwiched between two metal electrodes [8]. Therefore, the resistive switching device is suitable for wide application because of the simple preparation steps and relatively low cost.

B. Sun · Y. Liu $\cdot$ W. Zhao $\cdot$ P. Chen $(\square)$

School of Physics Science and Technology, Southwest University, Chongqing 400715, People's Republic of China

e-mail: pchen@swu.edu.cn

B. Sun $\cdot$ W. Zhao $\cdot$ J. Wu

Institute for Clean Energy \& Advanced Materials (ICEAM), Southwest University, Chongqing 400715, People's Republic of China
In the past few years, a new control method (light controlled) has been involved in the resistive switching memory device. Ungureanu firstly reported the lightcontrolled resistive switching memory in $\mathrm{Pd} / \mathrm{Al}_{2} \mathrm{O}_{3} / \mathrm{SiO}_{2}$ device [9]. At the same time, Adachi and Park also added the light as extra control parameter in the switching memory device based on $\mathrm{ZnO}$ nanorods [10-12]. In addition, our group also found that light can act as a control method in some resistive switching systems [1315]. The light-controlled resistive switching effect provides the potential for light-controlled nonvolatile memory device, which may be a promising developing trend of information science and storage technology. In addition, the white light, which is the most ordinary light source, is widely used.

$\mathrm{BaWO}_{4}$ is a wide gap semiconductor with $\mathrm{Eg}>4.9 \mathrm{eV}$ and has a Scheelite structure [16, 17]. $\mathrm{BaWO}_{4}$ is an important material in the electro-optical industry owing to its emission of blue luminescence [18-23]. Therefore, $\mathrm{BaWO}_{4}$ received more and more research interest [24].

Although there are many reports about various applications in $\mathrm{BaWO}_{4}$ nanostructure in previous works, the resistive switching properties of $\mathrm{BaWO}_{4}$ have not been reported yet. Herein we present the reversible bipolar resistive-switching effect in $\mathrm{Ag} / \mathrm{BaWO}_{4} / \mathrm{FTO}$ device. Moreover, the resistive-switching effect can be controlled by white-light illumination. 


\section{Experimental}

\subsection{Preparation of $\mathrm{BaWO}_{4}$ Nanospheres}

The $\mathrm{BaWO}_{4}$ nanospheres were prepared by a hydrothermal process using cetyltrimethylammonium bromide (CTAB) as the surfactant. All the chemicals used in this work were of analytical grade and used directly without further purification. The distilled water was used as a solvent throughout the experiment. Firstly, $\mathrm{Ba}\left(\mathrm{NO}_{3}\right)_{2}(0.01 \mathrm{M})$ and $\mathrm{Na}_{2} \mathrm{WO}_{4} \cdot 2 \mathrm{H}_{2} \mathrm{O}(0.01 \mathrm{M})$ were dissolved in $40 \mathrm{ml}$ distilled water under stirring continuously. Then $0.5 \mathrm{~g}$ cationic surfactant cetyltrimethylammonium bromide (CTAB) was added into above solution under strong stirring. After continuous stirring for $2 \mathrm{~h}$, the solution was transferred to a 50 -ml sealed Teflon-lined steel autoclave. Then, the sealed Teflon-lined steel autoclave was heated and kept at $200{ }^{\circ} \mathrm{C}$ for $72 \mathrm{~h}$. After the autoclave was cooled to room temperature, the powder obtained was washed with distilled water and ethanol and dried at $60{ }^{\circ} \mathrm{C}$ for $12 \mathrm{~h}$.

\subsection{Preparation of $\mathrm{Ag} / \mathrm{BaWO}_{4} / \mathrm{FTO}$ Device}

Firstly, FTO substrates were cleaned by acetone, ethanol, and deionized water, and subsequently dried on the spin coater. Secondly, $\mathrm{BaWO}_{4}$ films were prepared on FTO substrate by spin-coating method. The detail preparation process of $\mathrm{BaWO}_{4}$ films is as follows: Firstly, we grinded the as-prepared $\mathrm{BaWO}_{4}$ nanospheres powder for $2 \mathrm{~h}$. Next, we dissolved the powder in toluene solution to prepare precursor gel. Then the precursor gel was spin-coated on the FTO substrate. The spin-coating process at 5,000 rpm for $10 \mathrm{~s}$ was used to prepare $\mathrm{BaWO}_{4}$ films with thickness of about $2 \mu \mathrm{m}$. Then these samples were subsequently dried at $60{ }^{\circ} \mathrm{C}$ in vacuum for overnight. The thickness of the $\mathrm{BaWO}_{4}$ film was detected by the step profiler.

\section{Characterizations}

Crystal structure of $\mathrm{BaWO}_{4}$ nanospheres was characterized by $\mathrm{X}$-ray diffraction (XRD) with $\mathrm{Cu} K \alpha$ radiation at room temperature. Surface morphology of $\mathrm{BaWO}_{4}$ nanospheres was characterized using scanning electron microscope (SEM). Microstructure, nanosphere size, selected area electron diffraction (SAED) pattern, and the energy-dispersive X-ray spectroscopy (EDX) spectra of the $\mathrm{BaWO}_{4}$ nanospheres were observed by transmission electron microscopy (TEM) at an acceleration voltage of $200 \mathrm{kV}$. In the test of resistive switching characterizations, Ag is top electrode and FTO is bottom electrode, as shown in Fig. 1. Ag electrodes with area of $\sim 1 \mathrm{~mm}^{2}$ and thickness of $200 \mathrm{~nm}$ were prepared by vacuum deposition. And the

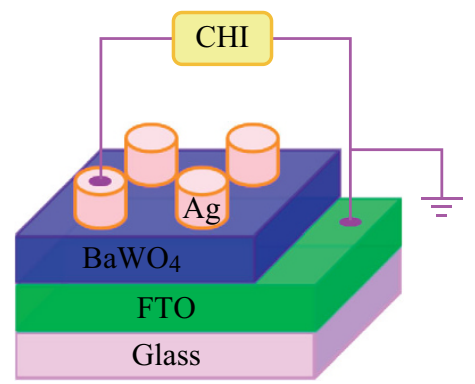

Fig. 1 The schematic representation of $I-V$ measurement

preparation process of Ag electrodes is as follows: Firstly, we covered a mask on surface of $\mathrm{BaWO}_{4} / \mathrm{FTO}$. Secondly, we put it into the vacuum sputtering system to grow $\mathrm{Ag}$ electrodes. Finally, we chose the superior electrodes for characterization. Current-voltage $(I-V)$ and resistance cycles curves were tested using the electrochemical workstation $(\mathrm{CHI})$ at room temperature. In addition, we used an ordinary filament lamp as light source. The wavelength range of light is $400-760 \mathrm{~nm}$.

\section{Results and Discussion}

Figure 1 shows the schematic representation of the device for $I-V$ measurement, where the $\mathrm{BaWO}_{4}$ film with thickness of $\sim 2 \mu \mathrm{m}$ was spin coated on the FTO substrate, and the electrodes of $\mathrm{Ag}$ with the area of less than $1 \mathrm{~mm}^{2}$ and thickness of $200 \mathrm{~nm}$ were deposited onto the $\mathrm{BaWO}_{4}$ film.

Scanning electron microscope (SEM) image of the asprepared $\mathrm{BaWO}_{4}$ nanospheres is shown in Fig. 2a. The asprepared sample consists of $\mathrm{BaWO}_{4}$ nanospheres. And the size of these nanospheres is about $180-220 \mathrm{~nm}$ from the transmission electron microscopy (TEM) image in Fig. $2 b$. From the high-resolution transmission electron microscopy (HRTEM) image of $\mathrm{BaWO}_{4}$ nanospheres in Fig. 2c, the lattice spacing between two planes is $\sim 0.25 \mathrm{~nm}$, corresponding to the (101) planes of $\mathrm{BaWO}_{4}$. Figure $2 \mathrm{~d}$ exhibits the selected area electron diffraction (SAED) pattern of the $\mathrm{BaWO}_{4}$ nanospheres, where the corresponding nearest four spots in the figure can be indexed to (110), (220), (002), and (004) planes of $\mathrm{BaWO}_{4}$, indicating that as-prepared $\mathrm{BaWO}_{4}$ nanospheres possess an excellent single-crystal structure.

The crystalline structure of the $\mathrm{BaWO}_{4}$ nanospheres was characterized by XRD. Figure $3 \mathrm{a}$ exhibits the XRD pattern of as-prepared $\mathrm{BaWO}_{4}$ nanospheres. There are only the peaks of $\mathrm{BaWO}_{4}$, which reveals the purity of the $\mathrm{BaWO}_{4}$ nanospheres. The XRD demonstrates the characteristic diffraction peaks of $\mathrm{BaWO}_{4}$. Moreover, the XRD profile matches very well with that in the reported work [25-28]. The result indicates that the $\mathrm{BaWO}_{4}$ nanospheres have a 

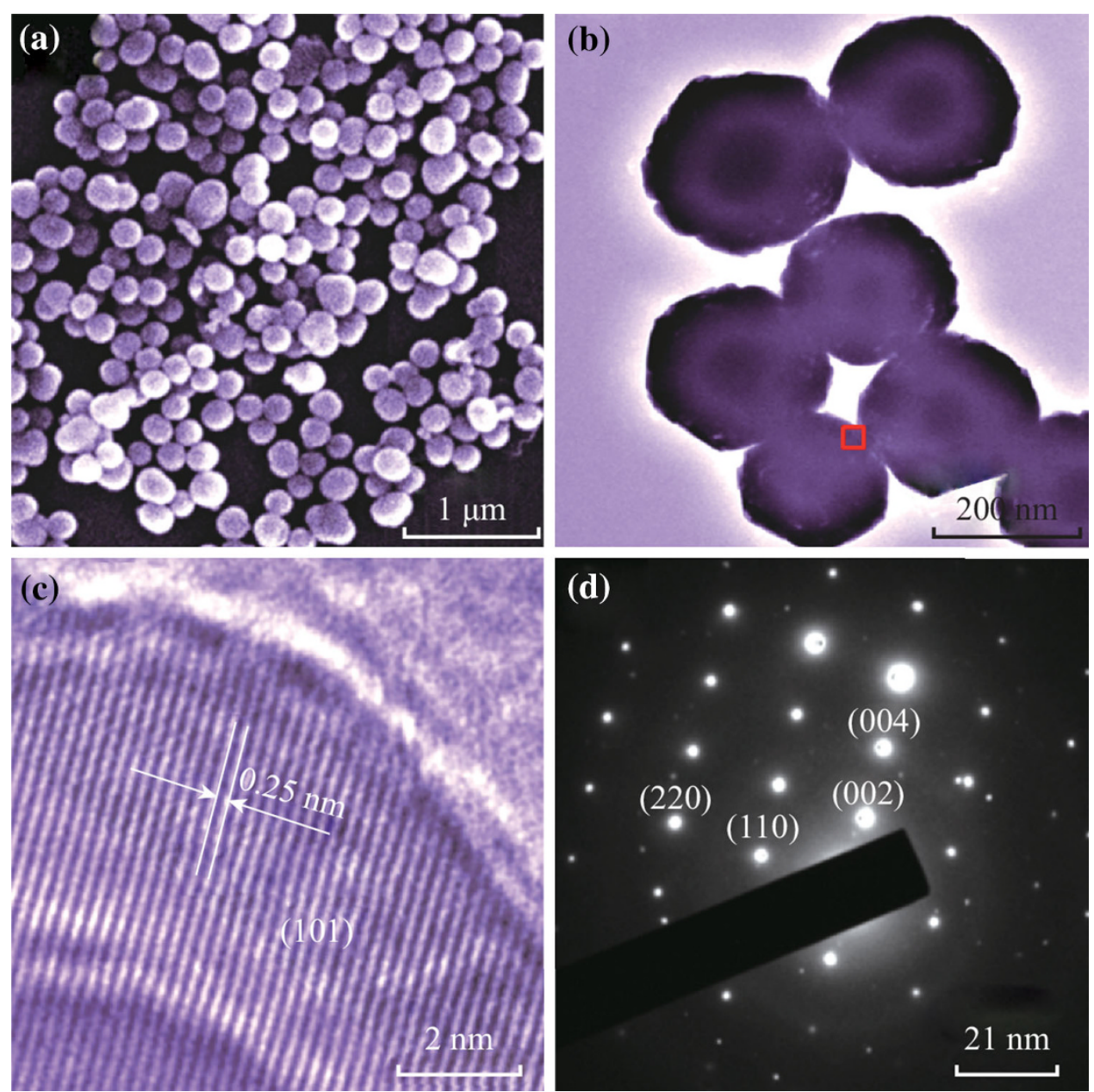

Fig. 2 a The SEM image of the as-prepared $\mathrm{BaWO}_{4}$ nanospheres. $\mathbf{b}$ The TEM image of $\mathrm{BaWO}_{4}$ nanospheres. $\mathbf{c}$ The HRTEM of a typical portion recorded in the rectangular area of part (b). d The SAED pattern of $\mathrm{BaWO}_{4}$ nanospheres
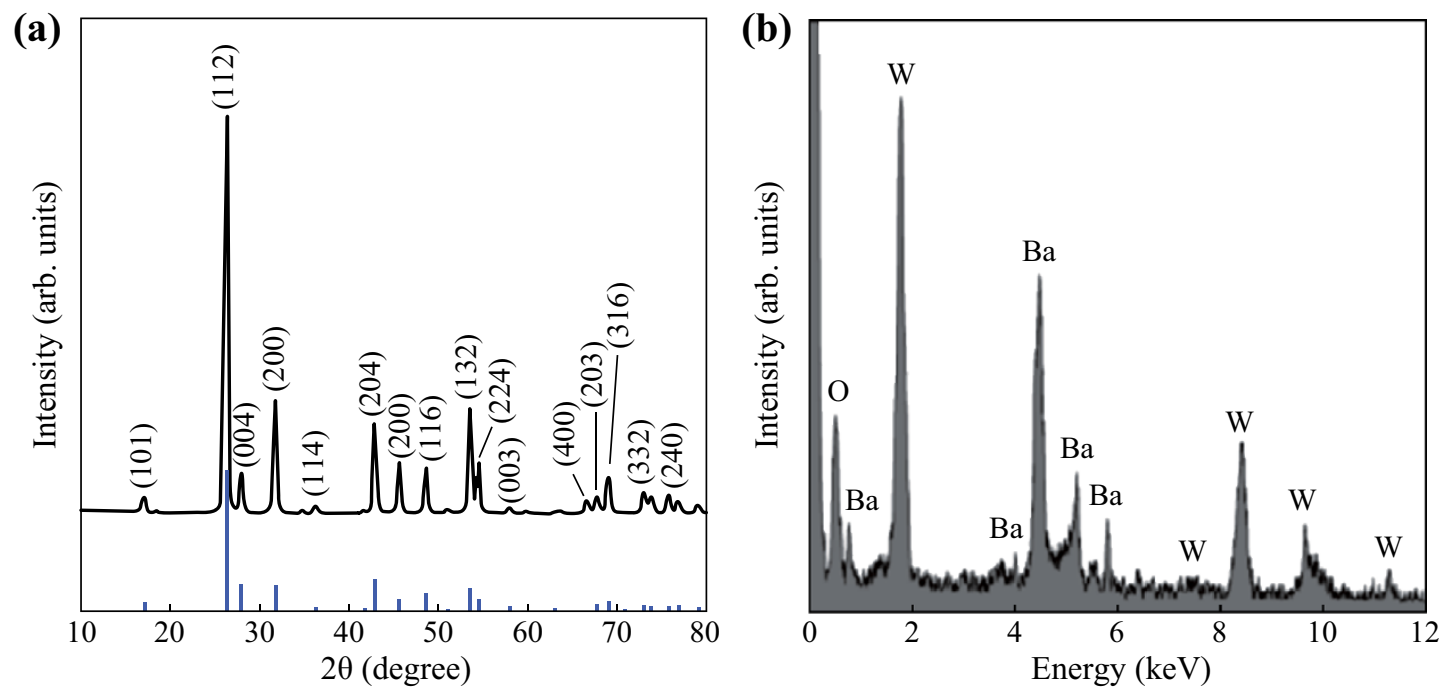

Fig. 3 a The XRD of as-prepared $\mathrm{BaWO}_{4}$ nanospheres at room temperature. b The EDX spectrum of $\mathrm{BaWO}_{4}$ nanospheres 
tetragonal scheelite unit cell $(a=5.62 \pm 0.05 \AA$, $c=12.71 \pm 0.07 \AA$ ) according to the peak positions and their relative intensities, which is consistent with the reported value (JCPDS Cards 08-457). Therefore, the product contains only pure $\mathrm{BaWO}_{4}$, and the sharp peaks demonstrate good crystallinity of the $\mathrm{BaWO}_{4}$ nanospheres. The composition of $\mathrm{BaWO}_{4}$ nanospheres was further confirmed by elemental analysis carried out with energy-dispersive X-ray spectra (EDX). The EDX data in Fig. 3b confirm that the compositions of as-prepared product are only $\mathrm{Ba}, \mathrm{W}$, and $\mathrm{O}$ with an atomic ratio of 0.93:0.98:4, which is close to the stoichiometric ratio of $\mathrm{BaWO}_{4}$.

Figure 4a displays the $I-V$ characteristics curves of $\mathrm{Ag} /$ $\mathrm{BaWO}_{4} / \mathrm{FTO}$ device in linear scale in the dark and under white-light illumination with power density of $30 \mathrm{~mW}$ $\mathrm{cm}^{-2}$, we can see that $I-V$ curves exhibit asymmetric behavior with significant hysteresis. The arrows in the figure denote the sweeping direction of voltage.

Figure $4 \mathrm{~b}$ presents a corresponding $I-V$ curve of $\mathrm{Ag} /$ $\mathrm{BaWO}_{4} / \mathrm{FTO}$ device in logarithmic scale. The arrows in the figure denote the sweeping direction of voltage. The Ag/ $\mathrm{BaWO}_{4} / \mathrm{FTO}$ device shows obvious resistive switching behavior in the dark. A sudden current increasing occurs at $3.0 \mathrm{~V}\left(V_{\mathrm{Set}}\right)$, indicating a resistive switching from the highresistance state (HRS or 'OFF') to the low-resistance state (LRS or 'ON'), which was called the "Set" process. When the applied voltage sweeps from zero to negative voltage of about $-3.5 \mathrm{~V}$ ( $\left.V_{\text {Reset }}\right)$, the device can return to the HRS, which was called the "Reset" process. The resistances of HRS and LRS at negative bias are much larger than those at positive bias. During the successive "Set" and "Reset" cycles on the same device, the device shows the identical $I-V$ curves. The $V_{\text {Reset }}$ and $V_{\text {Set }}$ are almost unchanged in subsequent cycles for the same device (not shown here). Moreover, the resistive switching behavior of $\mathrm{Ag} / \mathrm{BaWO}_{4} /$ FTO device is improved by white-light illumination. The $I-$ $V$ curve under white-light illumination is more symmetrical than that in the dark. And the resistive switching behavior at negative bias is more obvious than that in the dark. Furthermore, the resistance of LRS at negative bias is nearly as same as that at positive bias. In addition, the $V_{\text {Set }}$ $(3.1 \mathrm{~V})$ under white-light illumination is larger than that $(3.0 \mathrm{~V})$ in the dark.

In order to estimate the probable practicability of the white-light-controlled resistive switching behaviors of the $\mathrm{Ag} / \mathrm{BaWO}_{4} / \mathrm{FTO}$ device, the resistance cycles number curves for the HRS and LRS with a positive bias of $1.0 \mathrm{~V}$ in the dark and under illumination with power density of 30 $\mathrm{mW} \mathrm{cm}^{-2}$ are tested and shown in Fig. 5. The resistances are about $25 \mathrm{k} \Omega$ at the LRS (ON state) and $400 \mathrm{k} \Omega$ at the HRS (OFF state) in the dark, indicating the OFF/ON-state resistance ratio is up to 16 . However, the resistances are about $20 \mathrm{k} \Omega$ at the LRS (ON state) and $300 \mathrm{k} \Omega$ at the HRS (OFF state) under white-light illumination, suggesting the $\mathrm{OFF} / \mathrm{ON}$-state resistance ratio is 15 . More importantly, the resistances of the LRS (ON state) and the HRS (OFF state) are nearly unchanged after 50 cycles for the device in the dark and under white-light illumination, which indicates the good stability of the white-light-controlled resistive switching behaviors of the $\mathrm{Ag} / \mathrm{BaWO}_{4} / \mathrm{FTO}$ device. According to the above results, the steady white-lightcontrolled resistive switching behavior in $\mathrm{Ag} / \mathrm{BaWO}_{4} / \mathrm{FTO}$
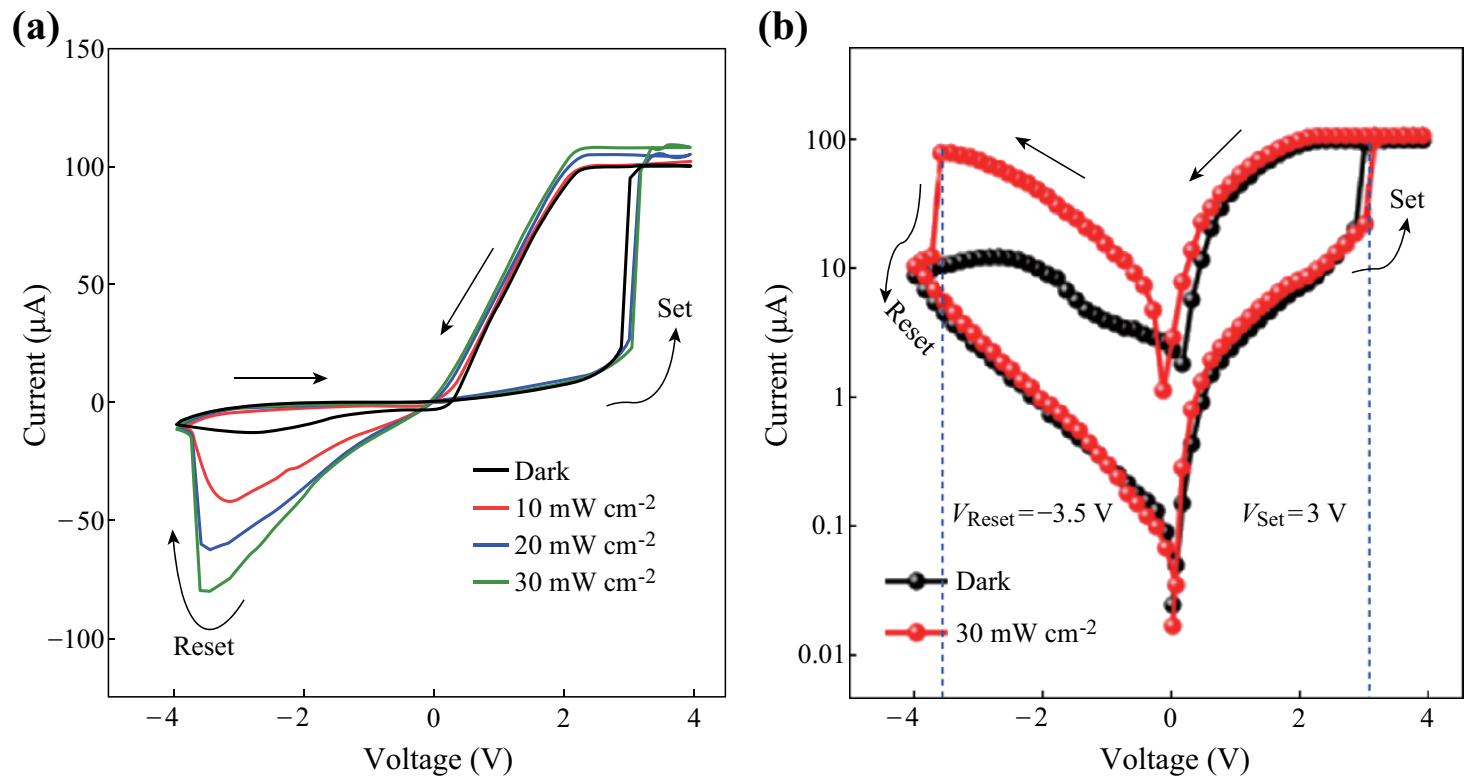

Fig. 4 a The $I-V$ characteristic curves in linear scale of $\mathrm{Ag} / \mathrm{BaWO}_{4} / \mathrm{FTO}$ structure in the dark and under white-light illumination with power density of $30 \mathrm{~mW} \mathrm{~cm}{ }^{-2}$. b The corresponding $I-V$ characteristic curves in logarithmic scale 


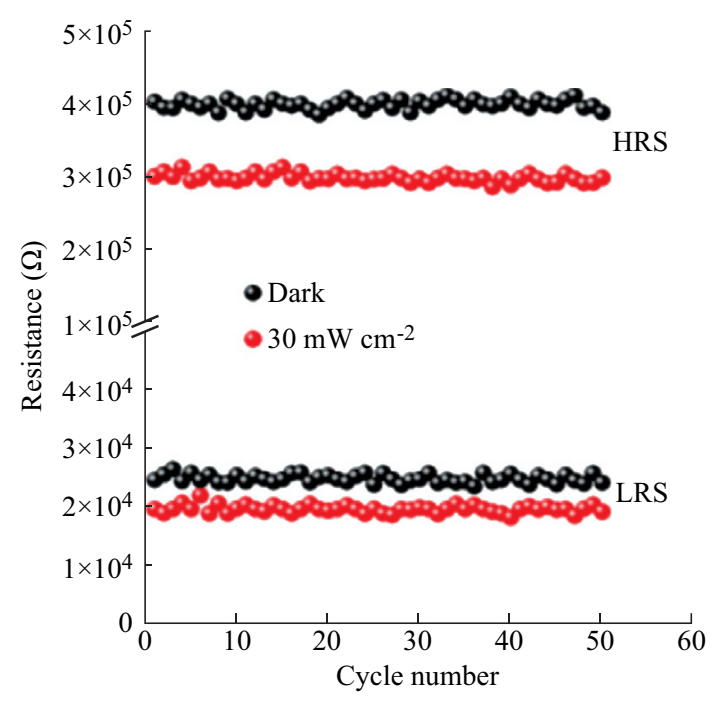

Fig. 5 The resistance cycles curve with a positive bias voltage of $1.0 \mathrm{~V}$ in the dark and under white-light illumination with power density of $30 \mathrm{~mW} \mathrm{~cm} \mathrm{~cm}^{-2}$

structure provides the potential for light-controlled nonvolatile optoelectronic memory applications.

The mechanism for resistive switching in a metal/oxides/oxides structure has been extensively investigated $[8$, 29-33]. In our works, current-voltage curve of the Ag/ $\mathrm{BaWO}_{4} / \mathrm{Ag}$ structure is symmetrically linear without hysteresis (not shown here), indicating it is Ohmic contact between $\mathrm{Ag}$ and $\mathrm{BaWO}_{4}$. Therefore, the asymmetric behavior of $I-V$ curve of $\mathrm{Ag} / \mathrm{BaWO}_{4} / \mathrm{FTO}$ in the dark indicates that a Schottky barrier is formed at the interface of $\mathrm{BaWO}_{4} / \mathrm{FTO}$. The bipolar resistive switching behavior of $\mathrm{Ag} / \mathrm{BaWO}_{4} / \mathrm{FTO}$ should result from the trapped and detrapped charge in the Schottky-like depletion layer [2631]. Moreover, the white light can generate a large number of charges, which can change the trapped state and detrapped state in the Schottky-like depletion layer [9-12]. Therefore, the white light can modulate the resistive switching behavior of $\mathrm{Ag} / \mathrm{BaWO}_{4} / \mathrm{FTO}$.

\section{Conclusions}

$\mathrm{BaWO}_{4}$ nanospheres were prepared by hydrothermal process. The reversible bipolar resistive switching characteristics of $\mathrm{Ag} / \mathrm{BaWO}_{4} / \mathrm{FTO}$ device were observed. In particularly, the resistance switching behavior can be controlled by white-light illumination. Therefore, the superior resistance switching characteristics of the $\mathrm{Ag} /$ $\mathrm{BaWO}_{4} / \mathrm{FTO}$ device hold a promise for light-controlled nonvolatile memory applications.
Acknowledgments This work was supported by the National Nature Science Foundation of China (Grant No. 51372209).

Open Access This article is distributed under the terms of the Creative Commons Attribution License which permits any use, distribution, and reproduction in any medium, provided the original author(s) and the source are credited.

\section{References}

1. X. Sun, G. Li, X. Zhang, L. Ding, W. Zhang, Coexistence of the bipolar and unipolar resistive switching behaviours in $\mathrm{Au} / \mathrm{SrTiO}_{3} /$ Pt cells. J. Phys D-Appl. Phys. 44(12), 125404 (2011). doi:10. 1088/0022-3727/44/12/125404

2. R. Waser, M. Aono, Nanoionics-based resistive switching memories. Nat. Mater. 6, 833-840 (2007). doi:10.1038/nmat2023

3. J.J. Yang, M.D. Pickett, X. Li, D.A.A. Ohlberg, D.R. Stewart, R.S. Williams, Memristive switching mechanism for metal/oxide/ metal nanodevices. Nat. Nanotechnol. 3, 429-433 (2008). doi:10. 1038/nnano.2008.160

4. D.H. Kwon, K.M. Kim, J.H. Jang, J.M. Jeon, M.H. Lee, G.H. Kim, X.S. Li, G.S. Park, B. Lee, S. Han, M. Kim, C.S. Hwang, Atomic structure of conducting nanofilaments in $\mathrm{TiO}_{2}$ resistive switching memory. Nat. Nanotechnol. 5, 148-153 (2010). doi:10. 1038/nnano.2009.456

5. A. Sawa, Resistive switching in transition metal oxides. Mater. Today 11(6), 28-36 (2008). doi:10.1016/S1369-7021(08)70119-6

6. K. Oka, T. Yanagida, K. Nagashima, M. Kanai, T. Kawai, J.S. Kim, B.H. Park, Spatial nonuniformity in resistive-switching memory effects of NiO. JACS 133(32), 12482-12485 (2011). doi:10.1021/ja206063m

7. L. Goux, J.G. Lisoni, M. Jurczak, D.J. Wouters, L. Courtade, C. Muller, Coexistence of the bipolar and unipolar resistiveswitching modes in $\mathrm{NiO}$ cells made by thermal oxidation of $\mathrm{Ni}$ layers. J. Appl. Phys. 107, 024512 (2010). doi:10.1063/1.3275426

8. R. Zazpe, M. Ungureanu, F. Golmar, P. Stoliar, R. Llopis, F. Casanova, D.F. Pickup, C. Rogero, L.E. Hueso, Resistive switching dependence on atomic layer deposition parameters in $\mathrm{HfO}_{2}$-based memory devices. J. Mater. Chem. C 2(17), 3204-3211 (2014). doi:10.1039/c3tc31819b

9. M. Ungureanu, R. Zazpe, F. Golmar, P. Stoliar, R. Llopis, F. Casanova, L.E. Hueso, A light-controlled resistive switching memory. Adv. Mater. 24(18), 2496-2500 (2012). doi:10.1002/ adma.201200382

10. M. Adachi, Shape control of highly crystallized titania nanorods based on formation mechanism. J. Mater. Res. 27(2), 440-447 (2012). doi:10.1557/jmr.2011.393

11. J. Park, S. Lee, J. Lee, K. Yong, A light incident angle switchable $\mathrm{ZnO}$ nanorod memristor: reversible switching behavior between two non-volatile memory devices. Adv. Mater. 25(44), 6423-6429 (2013). doi:10.1002/adma.201303017

12. J. Park, S. Lee, K. Yong, Photo-stimulated resistive switching of ZnO nanorods. Nanotechnology 23(38), 385707 (2012). doi:10. 1088/0957-4484/23/38/385707

13. W.X. Zhao, Q.L. Li, B. Sun, Z. Shen, Y.H. Liu, P. Chen, Whitelight-controlled resistive switching effect in $\left[\mathrm{BaTiO}_{3} / \gamma-\mathrm{Fe}_{2} \mathrm{O}_{3}\right] /$ ZnO film. Solid State Commun. 194, 16-19 (2014). doi:10.1016/ j.ssc.2014.06.007

14. W.X. Zhao, B. Sun, Y.H. Liu, L.J. Wei, H.W. Li, P. Chen, Lightcontrolled resistive switching of $\mathrm{ZnWO}_{4}$ nanowires array. AIP Adv. 4, 077127 (2014). doi:10.1063/1.4891461

15. B. Sun, Q.L. Li, W.X. Zhao, H.W. Li, L.J. Wei, P. Chen, Whitelight-controlled resistance switching in $\mathrm{TiO}_{2} / \alpha-\mathrm{Fe}_{2} \mathrm{O}_{3}$ composite 
nanorods array. J. Nanopart. Res. 16, 2389-2395 (2014). doi:10. 1007/s11051-014-2389-Z

16. R. Lacomba-Perales, D. Errandonea, A. Segura, J. Ruiz-Fuertes, P. Rodríguez-Hernández, S. Radescu, J. López-Solano, A. Mujica, A. Munǒz, A combined high-pressure experimental and theoretical study of the electronic band-structure of scheelite-type $\mathrm{AWO}_{4}$ (A5Ca, Sr, Ba, Pb) compounds. J. Appl. Phys. 110, 043703 (2011). doi:10.1063/1.3622322

17. O. Gomis, J.A. Sans, R. Lacomba-Perales, D. Errandonea, Y. Meng, J.C. Chervin, A. Polian, Complex high-pressure polymorphism of barium tungstate. Phys. Rev. B 86, 054121 (2012). doi:10.1103/PhysRevB.86.054121

18. C. Zhang, E. Shen, E. Wang, Z. Kang, L. Gao, C. Hu, L. Xu, One-step solvothermal synthesis of high ordered $\mathrm{BaWO}_{4}$ and $\mathrm{BaMoO}_{4}$ nanostructures. Mater. Chem. Phys. 96, 240-243 (2006). doi:10.1016/j.matchemphys.2005.06.061

19. W. Ge, H. Zhang, J. Wang, J. Liu, X. Xu, X. Hu, J. Li, M. Jiang, Growth of large dimension $\mathrm{BaWO}_{4}$ crystal by the Czochralski method. J. Cryst. Growth 270, 582-588 (2004). doi:10.1016/j. jcrysgro.2004.06.031

20. W. Ge, H. Zhang, J. Wang, J. Liu, H. Li, X. Cheng, H. Xu, X. Xu, $\mathrm{X}$. Hu, M. Jiang, The thermal and optical properties of $\mathrm{BaWO}_{4}$ single crystal. J. Cryst. Growth 276, 208-214 (2005). doi:10. 1016/j.jcrysgro.2004.11.385

21. L.I. Ivleva, I.S. Voronina, P.A. Lykov, L.Y. Berezovskaya, V.V. Osiko, Growth of optically homogeneous $\mathrm{BaWO}_{4}$ single crystals for Raman lasers. J. Cryst. Growth 304, 108-113 (2007). doi:10. 1016/j.jcrysgro.2007.02.020

22. X. Zhang, Y. Xie, F. Xu, X. Tian, Growth of $\mathrm{BaWO}_{4}$ fishbonelike nanostructures in w/o microemulsion. J. Colloid Interf. Sci. 274, 118-121 (2004). doi:10.1016/j.jcis.2004.01.048

23. G. Blasse, G.J. Dirksen, Photo-luminescence of $\mathrm{Ba}_{3} \mathrm{~W}_{2} \mathrm{O}_{9}$-confirmation of a structural principle. J. Solid State Chem. 36(1), 124-126 (1981). doi:10.1016/0022-4596(81)90200-0

24. Y. Liu, Y. Chu, Surfactant-assisted synthesis of single crystal $\mathrm{BaWO}_{4}$ octahedral microparticles. Mater. Chem. Phys. 92(1), 59-63 (2005). doi:10.1016/j.matchemphys.2004.12.030
25. X. Zhao, T. Li, Y. Xi, D.H.L. Ng, J. Yu, Synthesis of $\mathrm{BaWO}_{4}$ hollow structures. Cryst. Growth Des. 6(10), 2210-2213 (2006). doi: $10.1021 / \mathrm{cg} 0601655$

26. L.S. Cavalcante, J.C. Sczancoski, L.F. Lima Jr, J.W.M. Espinosa, P.S. Pizani, J.A. Varela, E. Longo, Synthesis, characterization, anisotropic growth and photoluminescence of $\mathrm{BaWO}_{4}$. Cryst. Growth Des. 9(2), 1002-1012 (2009). doi:10.1021/cg800817x

27. H. Shi, X. Wang, N. Zhao, L. Qi, J. Ma, Growth mechanism of penniform $\mathrm{BaWO}_{4}$ nanostructures in catanionic reverse micelles involving polymers. J. Phys. Chem. B 110(2), 748-753 (2006). doi:10.1021/jp0545694

28. A. Shih, W.D. Zhou, J. Qiu, H.J. Yang, S.Y. Chen, Z.T. Mi, I. Shih, Highly stable resistive switching on monocrystalline $\mathrm{ZnO}$. Nanotechnology 21(12), 125201 (2010). doi:10.1088/0957-4484/ 21/12/125201

29. T.L. Qu, Y.G. Zhao, D. Xie, J.P. Shi, Q.P. Chen, T.L. Ren, Resistance switching and white-light photovoltaic effects in Bi$\mathrm{FeO}_{3} / \mathrm{Nb}-\mathrm{SrTiO}_{3}$ heterojunctions. Appl. Phys. Lett. 98(17), 173507 (2011). doi:10.1063/1.3584031

30. N. Li, F. Gao, L. Hou, D. Gao, dna-templated rational assembly of $\mathrm{BaWO}_{4}$ nano pair-linear arrays. J. Phys. Chem. C 114, 16114-16121 (2010). doi:10.1021/jp101292c

31. X.G. Chen, J.B. Fu, S.Q. Liu, Y.B. Yang, C.S. Wang, H.L. Du, G.C. Xiong, G.J. Lian, J.B. Yang, Trap-assisted tunneling resistance switching effect in $\mathrm{CeO}_{2} / \mathrm{La}_{0.7}\left(\mathrm{Sr}_{0.1} \mathrm{Ca}_{0.9}\right)_{0.3} \mathrm{MnO}_{3}$ heterostructure. Appl. Phys. Lett. 101(15), 153509 (2012). doi:10.1063/ 1.4760221

32. A. Sawa, T. Fujii, M. Kawasaki, Y. Tokura, Hysteretic currentvoltage characteristics and resistance switching at a rectifying Ti/ $\mathrm{Pr}_{0.7} \mathrm{Ca}_{0.3} \mathrm{MnO}_{3}$ interface. Appl. Phys. Lett. 85(18), 4073-4075 (2004). doi:10.1063/1.1812580

33. D. Ielmini, C. Cagli, F. Nardi, Y. Zhang, Nanowire-based resistive switching memories: devices, operation and scaling. J. Phys D-Appl. Phys. 46(7), 074006 (2013). doi:10.1088/0022-3727/46/ 7/074006 